\title{
Finding the middle ground: how kinetochores power chromosome congression
}

\author{
Geert J. P. L. Kops • Adrian T. Saurin • \\ Patrick Meraldi
}

Received: 17 February 2010/ Accepted: 17 February 2010/Published online: 16 March 2010

(c) The Author(s) 2010. This article is published with open access at Springerlink.com

\begin{abstract}
Genomic stability requires error-free chromosome segregation during mitosis. Chromosome congression to the spindle equator precedes chromosome segregation in anaphase and is a hallmark of metazoan mitosis. Here we review the current knowledge and concepts on the processes that underlie chromosome congression, including initial attachment to spindle microtubules, biorientation, and movements, from the perspective of the kinetochore.
\end{abstract}

Keywords Kinetochore $\cdot$ Spindle $\cdot$ Mitosis .

Chromosome $\cdot$ Microtubule $\cdot$ Metaphase $\cdot$ Congression

\section{A brief synopsis of mitosis}

The generation of two genetically identical daughter cells from a single mother cell requires duplication of the genome and the subsequent physical separation of the two duplicates. This separation occurs during the process of mitosis, after the replicated genomes in the form of distinct chromosomes attach to fibers of the spindle apparatus coming from opposite directions and align on the cell equator. Shortly after all chromosomes have aligned in this

G. J. P. L. Kops $(\bowtie) \cdot$ A. T. Saurin

Department of Physiological Chemistry and Cancer Genomics

Centre, University Medical Center Utrecht, Stratenum 3.217,

Universiteitsweg 100, 3584 CG Utrecht, The Netherlands

e-mail: g.j.p.l.kops@umcutrecht.nl

P. Meraldi $(\square)$

Institute of Biochemistry, ETH Zurich, Schafmattstr. 18, HPM D6.5, 8093 Zurich, Switzerland

e-mail: patrick.meraldi@bc.biol.ethz.ch fashion, each chromosome copy is dragged to opposite sides of the cell after which the cell cleaves in the middle. These basic principles of cell division and segregation of chromosomes (so named by Heinrich Waldeyer in 1888 for their ability to be stained with a colored dye [1]) have been extensively documented since Walther Flemming first drew the events that precede division of a living salamander larvae epithelial cell in 1879 , a process he later referred to as mitosis [2,3]. Two decades later, inspired by the ideas of Theodor Boveri and other cytologists of that era who proposed that each chromosome possesses 'individuality' [4], Walter Sutton realized that inherited traits as described by Mendel might be intrinsic to the chromosomes. He then formulated the first chromosomal theory of heredity [5], but it was not until 1910 that Thomas Morgan proved this theory to be correct when he showed that the trait for eye color in fruit flies resided on the female sex chromosome [6]. Importantly, Boveri's 1902 work on sea urchin eggs fertilized by two sperm indicated that errors in chromosome partitioning correlated with defects in embryonic development. He then postulated in 1914 that chromosome aberrations and multiplications might also underlie malignancies [7], a hypothesis that has drawn significant interest to this day (e.g., $[8,9])$. So in essence, it has been understood for over a century that proper development of an organism and the maintenance of healthy tissues relies on faithful segregation of chromosomes and that this is achieved by attaching the chromosome copies to fibers that pull each copy in opposite directions. Since then, many conceptual and molecular advances have hugely increased our understanding of this fascinating process. Here, we will attempt to review the current knowledge on how chromosomes obtain and maintain productive attachments to the spindle fibers and how this results in correct chromosome positioning prior to segregation. 


\section{The meaning of metaphase}

The cytologists of the late-19th and early 20th century noted that chromosomes were aligned on the cell equator before chromosome segregation, or anaphase, initiated. This aligned configuration, also known as the metaphase plate, is a common feature of metazoan cell division, suggesting that moving all chromosomes to the middle of the spindle, a process referred to as chromosome congression [10], imparts some benefit to the division process. This was, in fact, investigated in spermatocytes of various species of praying mantids and grasshoppers. In those cells, normally occurring sex trivalents $\mathrm{XXY}$, in which the two $\mathrm{X}$ chromosomes are attached to one pole, and paired with one Y-chromosome that is attached to the opposite pole) were always positioned on the cell equator [11]. In contrast, experimentally created autosome trivalents, made by irradiating the spermatocytes, did not congress to the equator. The difference between the position of the 'old' and 'new' trivalents was correlated to the total length of fibers to each pole. While the length was equal for the 'new' trivalents (suggesting it had settled on the position at which the counteracting pulling forces from both poles were in balance, and was thus unaligned), the length of fibers from the 'old' sex-trivalent to each pole was shorter for the single chromosome. This suggested that the cell had accommodated pulling forces in such a way that the trivalent would end up at the equator. Selective pressure, therefore, possibly favors the configuration in which the trivalent was positioned similarly as the bivalent autosome pairs, namely on the metaphase plate. What might the benefit of this be? Various speculative reasons can be envisioned, including a more efficient anaphase, less chance of lagging chromosomes, or better coordination between anaphase and cytokinesis. Nevertheless, congression of chromosomes to the center of the spindle is not a universal trait, as many fungi and the generative cells of some plants have no metaphase plate [12-16]. So, at least in some species, metaphase has not proven beneficial to the division process, although the substantial differences in mitoses between these species and metazoans might underlie this difference. Although experimentally difficult to address, it would be interesting to see if metazoan mitoses, rather than the examples of meiosis described above, require a metaphase plate, or if such a plate is a mere consequence of the forces generated during the process of orientation of the chromosomes to opposite poles.

\section{Chromosome congression: a kinetochore-centric view}

The early drawings of mitosis showed that chromosomes attach to spindle fibers via a structure adjacent to the central constriction (see, for instance, the author's Fig. 64 in Ref. [3] or [17] for detailed reproductions). This structure was attributed kinetic properties for its ability to power chromosome movements and was named the kinetochore ('movement place') as early as 1934 by Lester Sharp (inspired by a suggestion of J.A. Moore ${ }^{1}$ ) and chosen as the preferred term in 1939 by Franz Schrader, who deemed it the most convenient of a list of proposed terms that included 'kinetic constriction' and 'fiber-attachment point' [18-20]. Compelling evidence that the kinetochore is a driving force behind chromosome congression has come from various studies that manipulated the chromosome to separate kinetochore regions from chromosome arms. Laser microsurgery of prometaphase chromosomes in PtK1 cells showed that separated chromosome fragments containing one kinetochore congressed with normal oscillatory behavior in half of the monitored events [21]. In another set of studies, mitotic centromere-kinetochore fragments (CKFs) were separated from the chromatin bulk by allowing progression to mitosis after hydroxyurea treatment. These cells undergo mitosis with unreplicated genomes (MUG) and careful analysis of mitotic figures in CHO MUGs [22] or live monitoring of HeLa MUGs [23] showed that the CKFs were able to congress. While these studies showed that kinetochores have activities that are sufficient to power chromosome congression, chromosome arms also contribute to the efficiency of the process. Microtubule motors of the chromokinesin family are present on chromosome arms, bind to astral microtubules, and propel the arms away from the pole, a process known as the polar ejection force (PEF). This force is sufficient to produce anti-poleward movements of mono-oriented chromosomes (where only one of the sisters has made attachments to one of the poles) in newt lung cells [24]. In meiotic extracts of Xenopus laevis oocytes, the chromokinesin Xkid (the principal generator of PEF [25]) is essential for chromosome congression [26, 27]. Inhibition of Kid in human cells however, although strongly reducing PEF, did not prevent the majority of chromosomes to congress in a normal amount of time $[28,29]$, suggesting that PEF is not

\footnotetext{
${ }^{1}$ We speculate that the J.A. Moore referred to by Sharp is John Alexander Moore (1915-2002), who later became Professor of Biology at UC Riverside. John Moore joined Columbia University (NYC, NY) in 1932 and as a freshman became acquainted with the leading biologists at Columbia, including E.B. Wilson and Lester Barth (Ruibal et al. Copeia 2001(4), p. 1155-1157). Despite his young age, Moore was not afraid to suggest an alternative theory on differentiation to the aged and esteemed E.B. Wilson. During those years, Lester Sharp taught at Cornell (Ithaca, NY) and given the fact that he himself was an esteemed cytologist, he likely interacted with colleagues and students at Columbia. Given John Moore's audacious nature, it is possible that on one of such occasions Moore approached Sharp with a suggestion on how he should name that 'movement place' on chromosomes, a suggestion Sharp later referred to in his 1934 classic work on cytology.
} 
essential for chromosome congression in human cells. Nevertheless, a significant fraction of chromosomes in Kid-antibody-injected cells remained stuck at a pole in a configuration that was identical to mono-oriented chromosomes in Kid-inhibited cells [29]. Thus, the PEF might increase the efficiency of congression by facilitating chromosome biorientation. Recent RNAi-mediated depletions of Kid or the Kid-localizing protein CHICA were reported to cause chromosome congression defects [30]. However, since the location of kinetochores was not monitored, one difficulty in interpreting these results is that the absence of PEF results in failed alignment of the arms, giving the impression of uncongressed chromosomes.

Contrary to the PEF, kinetochore activity is an absolute requirement of chromosome congression in all systems studied. Evidence for this comes from studies in which kinetochore-localized proteins that mediate kinetochoremicrotubule interactions were removed. Depletion of members of the conserved KMN network, which is essential for attachment, caused an inability of the unattached chromosomes to move to the equator [31-34]. Similarly, depletion of other kinetochore-localized, microtubule-binding proteins or protein complexes such as the Ska complex, the kinesin CENP-E, the plus-end tracking protein (+TIP) CLIP-170, or Cep57 resulted in a subset of unattached chromosomes that could not congress to the metaphase plate [35-47]. Thus, in cases where the PEF is presumably intact and kinetochore activity is affected, chromosomes cannot congress. It may be of interest to note that in cells depleted of the mentioned proteins, there seems to be almost always a subset of chromosomes that have congressed properly. This could reflect insufficient inhibition of the protein activities, or may point towards a specific role of any one protein in one of the steps that leads to congression, or to some redundancy between the various attachment networks that can be utilized depending on the context and position of the chromosomes upon mitotic entry. Interestingly, a recent study showed that kinetochore-fibers (K-fibers) are dispensable for congression [48]. Depletion of Nuf2 (an essential KMN network constituent) abolished $\mathrm{K}$-fibers, but allowed chromosomes congression in a CENP-E-dependent manner. Thus, although (CENP-Econtaining) kinetochores are needed for congression and stable K-fiber likely facilitate this process, K-fibers are not essential.

One possible exception to the 'no congression without kinetochores' rule is the cell-free Xenopus oocyte extract system. When DNA-coated beads and fluorochromelabeled tubulin were added to cytoplasmic extracts of metaphase II-arrested oocytes, a bipolar spindle formed around a group of beads that had at least occasionally lined up to form what resembled a metaphase plate [49].
Although this has been used as an argument that congression can occur without kinetochores, it was never shown that the beads indeed had congressed, i.e., that they reached a metaphase configuration from a disorganized starting point upon bipolar spindle assembly. Moreover, the fact that very similar spindles can be obtained with chromatin beads arranged in a geometry that is very different from a metaphase plate suggests that these experiments do not recapitulate chromosome congression, but rather show the ability of an assembly of immobile chromatin beads to generate a bipolar spindle around them [50]. Importantly, in studies that used frog chromosomes instead of DNA-coated beads, congression again depended on kinetochore-localized, microtubulebinding proteins such as Ndc80, CENP-E, or Cep57 [34, $36,51]$. Considering all evidence, we favor the notion that kinetochores are indispensable for chromosome congression.

\section{Chromosome movements during congression}

\section{Initial contacts}

In metazoans, microtubule-mediated chromosome movement is initiated after nuclear envelope breakdown when the chromosomes come in contact with the cytoplasm and spindle microtubules. Prior to the onset of anaphase, all chromosomes must achieve biorientation, meaning that one copied strand (referred to as the sister chromatid) has made end-on attachments to microtubules from one pole while the other has attached to the opposite pole. A number of mechanisms that involve centrosomes, chromosomes, and spindle microtubules cooperate to ensure that chromosomes are captured and incorporated into the spindle rapidly (Fig. 1; reviewed in [52, 53]). As a rule, chromosomes that are closer to one of the poles make first contact with microtubules from that pole, either directly [54, 55], with help from the chromatin-generated, microtubule-stabilizing Ran-GTP gradient (reviewed in [56]) or with help from microtubules that were organized by kinetochores themselves [57]. This initial contact often occurs via kinetochore-mediated attachment to the side of the microtubule (aka the lattice). Such lateral interaction then causes the chromosome to be rapidly transported to the pole. It has been suggested for almost two decades that the poleward movement and perhaps even the very initial interaction with the microtubule lattice may be mediated by the minus-end-directed microtubule motor dynein. This idea was based on observations that a pool of dynein is located at kinetochores in mitosis, and that dynein in vitro motility on microtubules is similar to the rate of poleward motions of chromosomes in various organisms [55, 58]. 


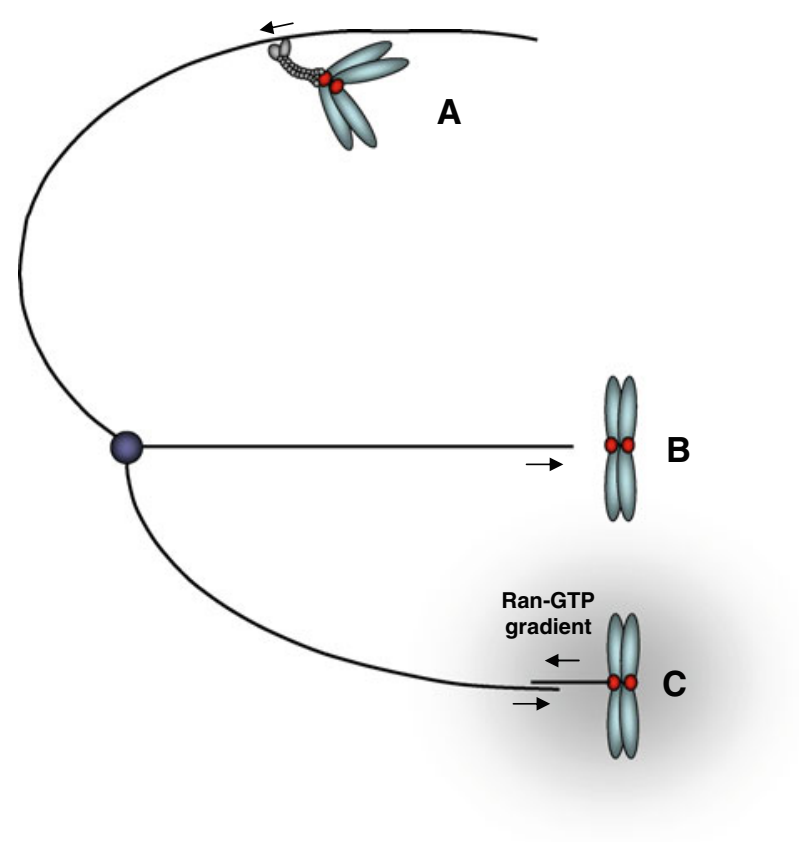

Fig. 1 Schematic depicting how kinetochores can initially interact with microtubules. a Lateral attachment to an astral microtubule and subsequent poleward transport by dynein motors. b Direct end-on attachment to the kinetochore. c Interaction between kinetochorenucleated microtubules (aided by the chromosomal Ran-GTP gradient) and microtubules emanating from the pole. Note that this might be an oversimplification, since the precise relationship between kinetochore-mediated microtubule nucleation and the more general Ran-GTP chromatin-induced microtubule nucleation is until now unclear

Only very recently was this shown to be indeed the case: Injection of antibodies to dynein heavy chain (DHC) in pig epithelial cells under conditions that allowed examination of only those poleward movements that resulted from chromosome-to-astral microtubule attachment, or depletion of the Zw10 protein that targets dynein to kinetochores, showed that dynein provided the required activity for poleward motions [59, 60]. Similarly, preventing stable end-on attachments in Xenopus S3 cells resulted in very rapid, predominantly poleward chromosome movements that depended on dynein and which resembled the early chromosome movements in prometaphase cells [61].

How critical to congression is the reeling-in of chromosomes by the pole? This question has turned out to be surprisingly difficult to answer. Studies in metazoans on inhibitions of dynein function have not led to a consensus on the role of dynein in congression, possibly because dynein's roles may vary between species and/or because of technical differences in the way dynein was inhibited. Global dynein inhibition from prophase onward (by injection of p50-dynamitin or DHC antibodies) in Xenopus or PtK1 cells showed no defects in metaphase alignment $[61,62]$, although a more extended global dynein inhibition by p50-dynamitin overexpression in COS-7 cells did report chromosome misalignments [63]. More specific inhibitions of dynein by removal of proteins required for dynein localization to kinetochores had either no effect (removal of Zw10 in Drosophila spermatocytes [64, 65]) or severe effects on chromosome alignment (Zw10 RNAi in human cells $[59,60]$ and CENP-F/NudE/NudEL RNAi or Spindly RNAi in human cells [66-68]), although some studies do not agree with those findings (NudEL antibody injection in pig cells [69], Spindly RNAi in human cells [70]). To complicate matters more, dynein is also required for generating tension between centromeres on bioriented sister chromatids [60, 62, 67, 69,71], and its inhibition is thus expected to result in destabilization of kinetochore microtubules and inefficient chromosome alignment independent of its role in initial lateral interactions and poleward movements. Thus, although it is clear that dynein powers poleward motions, it is unclear what the consequences to chromosome biorientation would be if poleward transport did not take place.

\section{Converting the initial contacts}

Once the chromosome has reached the pole, or possibly before, the lateral microtubule interaction is converted into an end-on attachment. This is somewhat of a 'black box' in mitosis research, as there are no clear studies in metazoans that show what happens during this transition (Fig. 2). Some ideas have come from studies that investigated the ten-subunit, budding yeast Dam1/DASH complex that both binds microtubules and localizes to kinetochores (reviewed in [72]). The Dam1/DASH complex can track the curling end of a depolymerizing microtubule, either as a 16-mer that forms a ring around the microtubule $[73,74]$ or as a single complex [75]. Microtubules to which a chromosome is laterally bound are still highly dynamic, and since microtubule depolymerization is fast, it could, in principle, catch up with the laterally attached chromosome even when it is being transported poleward by the Kar3p motor protein [76]. When such a depolymerizing fiber passes the kinetochore, the kinetochore may latch onto it by binding the Dam1/DASH complex/ring, in effect converting the lateral into an end-on-attachment. Although there is currently no evidence that this occurs in yeast cells, it provides an appealing model. Nevertheless, ring-like structures encircling the microtubules have not been identified in metazoans. Moreover, the Dam1 components appear to only have clear orthologs in fungal species [77].

So how might lateral-to-end-on conversion take place in metazoans? The KMN network is one of the core components of the microtubule attachment site on kinetochores required for stable, end-on attachments (reviewed in [72]). Co-inhibition studies of dynein and one of the KMN 

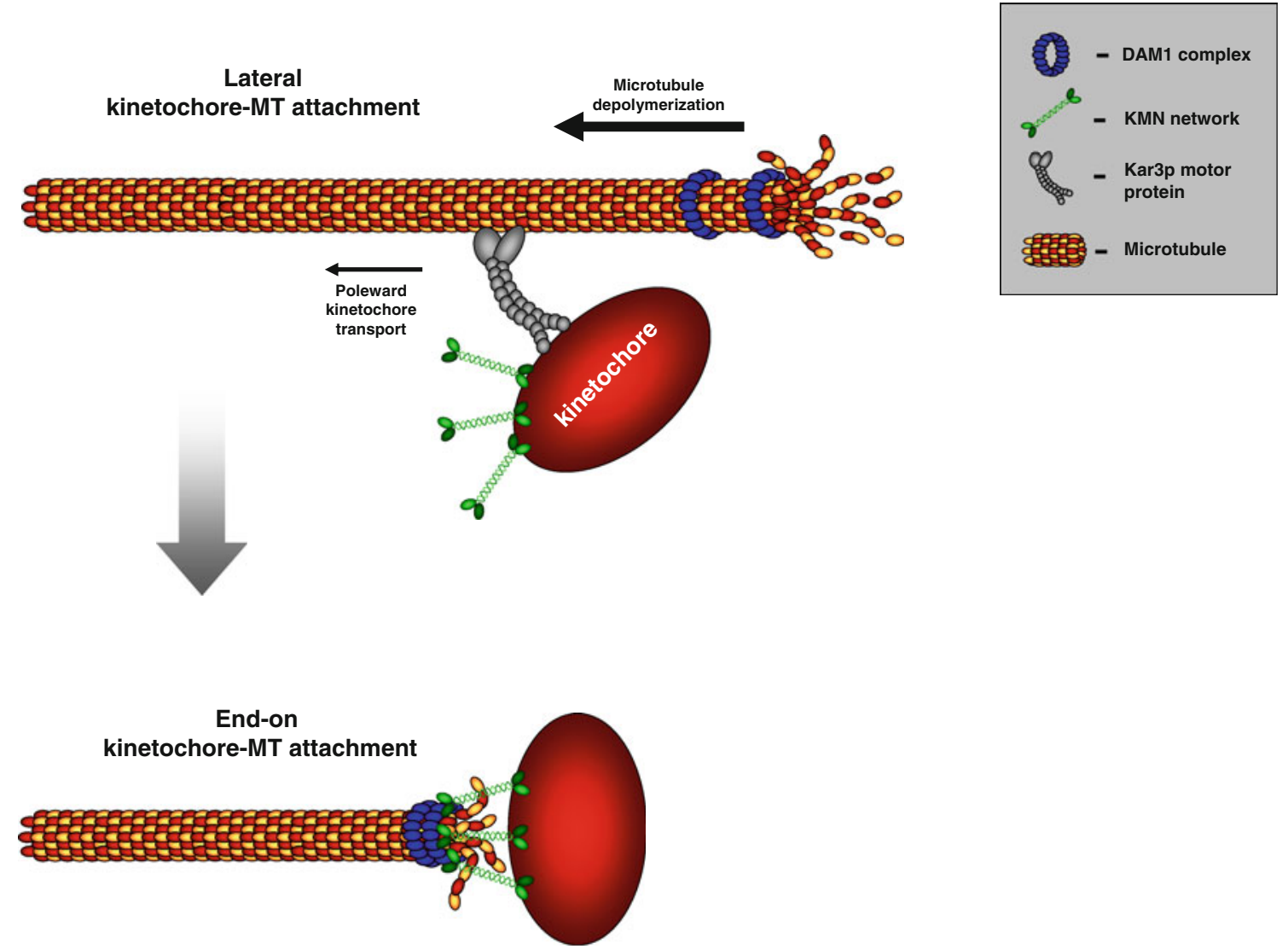

Fig. 2 The postulated mechanism for the conversion of lateral attachments into end-on attachments in Saccharomyces cerevisiae. Mono-oriented chromosomes are transported poleward by the Kar3p motor protein (dynein in metazoans). A depolymerizing microtubule accumulates the Dam1 complex (which is proposed to exist as a ring) around the plus-end. When the fast depolymerizing microtubule

network constituents Ndc80 in Xenopus S3 cells suggested that initial, dynein-dependent interactions of the kinetochore with the microtubule lattice are rapidly converted to an Ndc80-dependent end-on attachment [61]. Similar to the Dam1/DASH-mediated microtubule tracking of yeast chromosomes, a depolymerizing fiber that reaches the kinetochore could be grasped in an end-on fashion by kinetochore-bound Ndc80-complexes and drag the chromosome further poleward. In support of this, Ndc80 complexes can track depolymerizing microtubule fibers in vitro [78], as was shown for the Dam1/DASH complex [79, 80]. Furthermore, based on epistasis experiments in worms, Gassmann et al. [81] have posited a model in which the lateral-to-end on conversion is facilitated by interplay between the KMN network and dynein or dynein-bound proteins. In their model, the RZZ complex, which is required to tether dynein to kinetochores [65], reduces microtubule binding affinity of the KMN network, allowing transport of the chromosome towards the pole and passes the kinetochore, the Dam1 and the Ndc80 complex within the KMN network will interact to generate an end-on attachment. In metazoans, no clear Dam1 ortholog or plus-end tracking ring structure has been identified. The Ndc80 complex has been shown to track microtubule plus-ends and therefore this interaction may occur directly or through an unknown intermediate binding partner

preventing malorientation of the kinetochore. Upon encountering the plus-end of the depolymerizing microtubule, this inhibitory activity of the RZZ complex is somehow switched off, allowing the KMN network to generate stable end-on attachments. Interestingly, in PtK1 cells, inhibition of the Aurora B kinase, which normally decreases affinity of the Ndc 80 complex for microtubules [82, 83], prevented poleward movement of chromosomes, suggesting that microtubule-binding activity of Ndc80 may indeed need to be reduced for this to occur [84]. It remains to be investigated how RZZ exerts its control over the KMN network and if such control exists in vertebrate cells that have a significantly different chromosome architecture (reviewed in [85]). A second interesting vertebrate complex that can track depolymerizing microtubules is the Ska1/RAMA complex [37, 47]. Of particular interest is that the complex seems to be conserved in all eukaryotes, except fungi (P.M., unpublished result). Since the Dam1/ DASH and the Ska1/RAMA complex never seem to both 
be present in the same organism, this could indicate that in the course of evolution, fungal species have functionally replaced the Ska1 complex with the Dam1/DASH complex. Finally, the Bub1 protein kinase has been implicated in both yeast and human cells in the transition between lateral attachments and end-on attachments, as cells lacking Bub1 accumulate sister kinetochores with lateral attachments [86, 87]. These congression defects have been linked to the kinase activity of Bub1, however, it is presently unclear which Bub1 substrates control this transition $[88,89]$. It will thus be of interest to find out whether Bub1 phosphorylates and regulates any of the complexes that have been directly linked to this transition.

\section{Biorientation}

A mono-oriented chromosome that has been transported poleward and obtained an end-on attachment to one of its kinetochores now faces the daunting task of biorienting while being far removed from the distal pole to which it needs to make a connection. Two mechanisms have been put forward by which a pole-hugging chromosome could biorient (Fig. 3). In the first, a combination of factors contributes to an increased likelihood that the unattached kinetochore will encounter microtubules from the distal pole. These factors include sister kinetochore geometry to ensure that the unattached kinetochore faces that distal pole, the weak polar ejection force that could push the chromosome a little closer to the distal pole [29], the RanGTP gradient (reviewed in [56]), and kinetochore-derived microtubules that could mediate first contacts with the centrosomal microtubules that emanate from the distal pole (reviewed in [90]). However, microtubules from that pole would still have to travel significant distances. A second mechanism is based on observations that the unattached kinetochore of the mono-oriented chromosome attaches in a lateral fashion to stabilized kinetochore-fibers (K-fibers) that belong to an already bioriented and congressed chromosome pair [91]. A kinetochore-bound plus-end-directed microtubule motor such as CENP-E could then drive at least partial congression of the chromosomes to regions more central to the spindle where contacts with distal microtubules are easier to obtain. Such an elegant 'guiding' mechanism is likely to require flexibility of connection between the sister kinetochores, something that was recently shown to indeed be an intrinsic property of PtK1 chromosomes [92]. It is as yet unclear how chromosomes that congress in this way achieve biorientation, in other words, when and how they let go of the microtubule lattice and when and how they encounter the distal microtubules. The guiding mechanism also poses an interesting 'chickenand-egg' challenge: How did the chromosomes that provide the microtubule tracks themselves biorient? It is, of course, possible that the first chromosomes biorient by increasing the likelihood of encountering microtubules from distal poles, after which the K-fiber tracking mechanism kicks in to increase efficiency and speed of congression of the remaining chromosomes. Alternatively, a striking recent study showed that $\mathrm{K}$-fibers are, in fact, dispensable for guiding chromosomes, suggesting that the chromosomes may even use microtubule fibers that are not embedded in a kinetochore (and are thus highly unstable) to congress to the cell equator [48]. Finally, sister kinetochores on chromosomes that are close to the middle of the spindle might attach to microtubules from opposite sides (and thus biorient) simultaneously. When previously aligned, paired bivalents in grasshopper spermatocytes were detached from spindle fibers by micromanipulation, moved away from the metaphase plate and then allowed to re-establish connections with spindle microtubules [93], a subset of chromosomes achieved instant bi-orientation as deducted from the fact that upon reattachment they moved straight to the metaphase plate rather than to one of the poles first. High spatiotemporal resolution imaging of labeled chromosomes and kinetochores making initial contact with labeled microtubules upon nuclear envelope breakdown in vertebrate cells might answer what mechanisms function in conjunction with each other in order to establish biorientation of the full complement of chromosomes.

\section{Preventing and correcting malorientations}

When examining the processes of initial contacts and biorientation, one realizes that chromosomes can engage in a variety of erroneous attachments. Indeed, one in every $\sim 200$ divisions of human fibroblasts display lagging chromosomes during anaphase [94]. These laggers are a result of merotelic attachments, in which one kinetochore binds microtubules from both poles. Another type of misattachment is called syntely, in which both sister kinetochores have made attachments to microtubules emanating from the same pole. Although predicted to be quite a common event in the early phases of mitosis, the technical challenge of visualizing very transient syntelic attachments in unperturbed mitosis has made it difficult to estimate what the frequency of syntely is. Both merotelic and syntelic attachments need to be corrected for biorientation and error-free chromosome segregation to occur. The process of error-correction was beautifully visualized in cells that were allowed to build a bipolar spindle from a monopolar starting point [84]. In cells with a monopolar spindle, obtained by blocking the activity of the kinesin- 5 family member Eg5, many chromosomes have syntelic attachments. Re-activation of the Eg5 motor drives bipolarization of the spindle and all the previously formed 

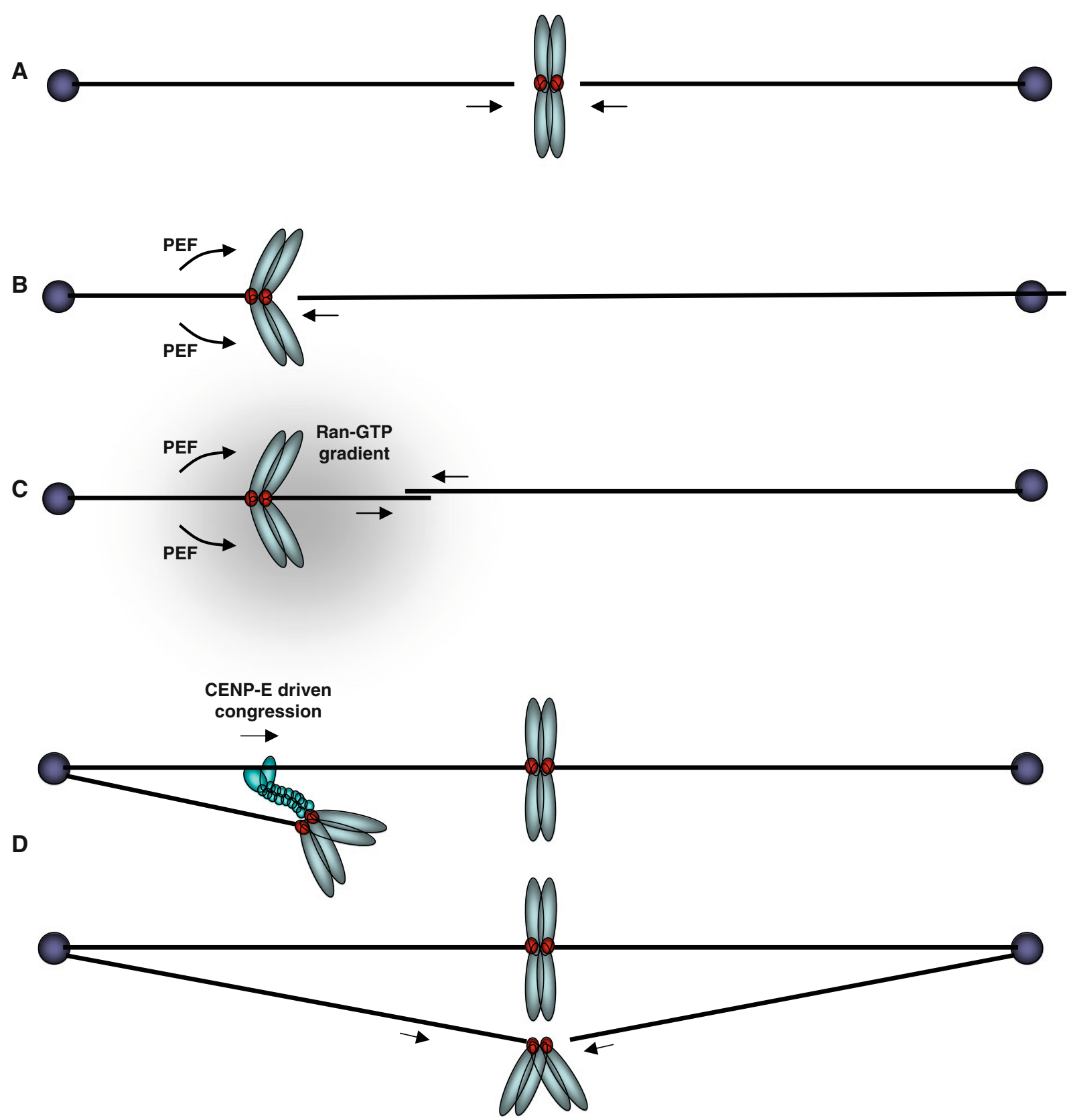

Fig. 3 The different routes to kinetochore biorientation. a Direct simultaneous end-on attachment of sister kinetochores with microtubules from both poles. b The mono-oriented sister chromosomes are pushed in an anti-poleward manner by PEF to increase the probability that the opposing sister kinetochore can make a direct end-on attachment with a microtubule from the opposite pole. c The chromosomal Ran-GTP gradient assists microtubule nucleation from

syntelic attachments are subsequently corrected [84]. Importantly, the correction process depends entirely on the Aurora B kinase. Inhibition of Aurora B during bipolar spindle formation prevented error-correction and resulted in bipolar spindles with many unaligned, syntelic chromosomes [84]. Similarly, adding Aurora B inhibitors during normal mitosis results in many persistent syntelic the kinetochore, which may then bind directly to microtubules from the distal pole. d The mono-oriented chromosome is transported towards the distal pole along an existing kinetochore fiber by the plusend directed motor, CENP-E, which binds to the unattached sister kinetochore. This increases the chance of encountering a microtubule emanating from the distal pole

and merotelic attachments [95-97], suggesting that these attachments occur in every cell division and are both normally corrected by Aurora B.

How does Aurora B correct erroneous attachment, and how does it leave correct ones alone? As it turns out, it's all about location, location, location. Aurora B is anchored in between sister kinetochores, in a chromatin region that is 
referred to as the inner centromere. From there, Aurora B can phosphorylate the Ndc80 subunit of the KMN network $[82,83]$. This phosphorylation lowers the affinity of the Ndc80 complex for microtubules, thus predicting to destabilize kinetochore-microtubule interactions. In support of this, PtK1 cells expressing a mutant Ndc80 protein lacking six or nine potential Aurora B phosphorylation sites contained many misaligned chromosomes that had apparent syntelic or merotelic attachments [32, 98]. Thus, by modifying the microtubule-binding affinity of the Ndc80 subunit, Aurora B can destabilize erroneous attachments. It is quite possible that Aurora B regulates error-correction on multiple levels by phosphorylating other kinetochore- or centromere-localized proteins that contribute to stable kinetochore attachments or microtubule stability. One such factor may be MCAK, a microtubule depolymerase that is localized to centromeres and kinetochores and that is directly inhibited upon phosphorylation by Aurora B [99-103]. Preventing or mimicking MCAK phosphorylation by Aurora B causes syntelic attachments [99] and MCAK is enriched at merotelic attachment sites in Xenopus S3 cells where it is phosphorylated by Aurora B [104]. Although some intriguing hypotheses have been put forward [105], it is unknown how inhibition of MCAK facilitates error-correction. Interestingly, Aurora B also phosphorylates two other MT depolymerases, Kif2a and Op18/Stathmin [106, 107], and it will be interesting to see if regulation of their activities contributes to the errorcorrection process as well. With this in mind, it is of interest to note that depletion of the Kif2a/MCAK-like kinesin-13 family member Kif2b was recently shown to reduce the fidelity of attachment-error-correction [108].

If Aurora B can destabilize attachments, why are correctly attached, bioriented chromosomes not detached from the spindle by Aurora B? Inspired by previous work [99, 109], Lens, Lampson and co-workers recently showed that tension generated by biorientation spatially separates the outer-kinetochore substrates of Aurora B, such as the Ndc80 complex, from the inner-centromere-localized kinase [110]. Although regulated phosphatase activities cannot be excluded by these studies, it provides a simple explanation for how productive, force-producing microtubule attachments are stabilized while erroneous ones that do not produce force, are not.

Aligning the chromosomes on the metaphase plate

One of the key questions of cell division is to understand how cells manage to precisely align the chromosomes in the middle of the spindle equator. This metaphase mechanics problem already fascinated cytologists in the first-half of the 20th century, in particular Östergren, who formulated in 1945 a conceptual hypothesis, which is still investigated as a serious possibility today [111]. Östergren postulated that chromosome movements on the metaphase plate are controlled by traction fibers (N.B. the concept of microtubules was unknown in 1945!), in which the poleward-pulling forces exerted by this fiber is proportional to the distance between the poles and kinetochores. As sister kinetochores are bioriented, this results at equilibrium in a position at the equator of the mitotic spindle. However, while research in the kinetochore field has made steady advances in the understanding of the molecular factors that control the initial attachment of kinetochores, the robust attachment to the plus-end of the spindle microtubules and the correction of defective (e.g., syntelic) attachments, our molecular understanding of the transition from bioriented attachment to fully aligned sister-kinetochore pairs is less well defined. Two extreme models are that chromosome alignment on the metaphase plate is an immediate downstream consequence of bioriented attachment, or that the chromosomes maintain a permanent position in the middle of the cells after initial congression has facilitated bioriented stable end-on attachments [48]. However, there is substantial evidence that the alignment on a metaphase plate is a dynamic and precisely regulated step of chromosome congression, at least in metazoans. Indeed, one can find perturbations that do not affect the ability of kinetochores to form bioriented, end-on attachments, yet still lead to chromosome alignment defects [113]. To align bioriented chromosomes on a metaphase plate, kinetochores are thought to use a combination of coupled microtubule depolymerization at the poleward-moving sister kinetochores and microtubule growth at the antipoleward-moving sister kinetochores. To comprehend chromosome alignment, it is therefore essential to understand how the growth and shrinkage of kinetochore-bound microtubules is regulated. However, one of the inherent difficulties in the study of the kinetochore-bound microtubules is that, with the exception of a restricted number of budding yeasts such as Saccharomyces cerevisiae, kinetochores are not just bound to one single spindle microtubule [114] but rather to a whole K-fiber, which contains bundles of several microtubules. K-fibers are assembled of 3-4 microtubules in organisms such as the fission yeast Schizosaccharomyces pombe, 10-12 microtubules in the fruit fly Drosophila melanogaster, or up to 25-30 bundled microtubules in mammalian cells [115-118]. Importantly, the relationship between the behavior of the individual kinetochore-microtubules and the whole $\mathrm{K}$-fiber is not necessarily linear. On the one hand, live-cell experiments with EB1-GFP-expressing cells show that microtubules bound to kinetochores moving in an anti-poleward manner accumulate EB1, while microtubules bound to polewardmoving kinetochores do not [119]. This would suggest that elongating $\mathrm{K}$-fibers contain a majority of growing 
microtubules. On the other hand, a high-resolution electron-microscopy study found in all K-fibers a mix of growing, shrinking, and pausing microtubules, with a surplus of shrinking microtubules [120]. Elongating K-fibers might thus contain a majority of shrinking microtubules, suggesting that overall $\mathrm{K}$-fiber dynamics is very different from the individual microtubule behavior. However, to date, we do not know how kinetochores coordinate the dynamics of these individual microtubules to generate directional movement.

So what do we know about the dynamics of K-fibers? Interestingly, kinetochore-microtubules have different dynamics than free spindle microtubules, as their tubulin turnover is known to be 20-fold lower [121]. These $\mathrm{K}$-fibers are also known to undergo poleward microtubule flux, a combination of microtubule plus-end polymerization and minus-end depolymerization at the spindle poles (microtubule treadmilling) and the sliding of microtubules within the fiber itself $[122,123]$. Nevertheless, even though microtubule flux/sliding has been implicated in force generation at kinetochores and is known to help separate the spindle poles [123-125], it does not appear to play a major role in chromosome alignment, as a severe reduction of microtubule flux does not impair metaphase plate formation [126].

Another clue as to which mechanisms might underlie chromosome alignment comes from one of the most striking features of the behavior of chromosomes, namely their directional instability (Fig. 4). In most metazoans, bioriented kinetochores do not move in a direct movement to the middle of the spindle, but rather undergo a series of regular oscillations [127]. Chromosome oscillation, defined as the regular movements of sisterkinetochore pairs along the spindle axis, have been described for the majority of metazoan cells for over 70 years [128, 129], leading to the concept that K-fibers possess a dynamic instability that is conceptually similar to the dynamic instability of free single microtubules. Such kinetochore oscillations are known for mitotic and meiotic systems and have been observed for monooriented and bioriented kinetochore pairs [127, 130, 131]. What is the nature of the forces that drive kinetochore oscillations? Elegant laser microsurgery experiments demonstrated that the oscillations are driven mostly by the action of the poleward-moving kinetochore and not the anti-poleward sister kinetochores [132]. This indicates that kinetochores are mostly exerting a pulling force on chromosomes instead of a pushing force, implying that kinetochores use microtubule depolymerization as the main energy source for the alignment of bioriented kinetochores. Nevertheless, it is important to note that kinetochores can also exert pushing forces on the spindle in mammalian cells, suggesting that microtubule polymerization can also contribute to force generation in certain circumstances $[125,133]$. The other potential important contributors to the generation of kinetochore oscillation are the microtubule motors that control the PEF. Indeed there is very strong evidence that monooriented kinetochores oscillate as a consequence of the balance of forces between PEF and poleward movement due to microtubule depolymerization [24, 29]. It has also been proposed that the PEF is responsible for the oscillations of bioriented kinetochores [29], however recent experiments suggest that the PEF might not drive kinetochore oscillation, but rather limit their amplitude [134].

Which are the other kinetochore-specific molecular components that are potentially implicated in kinetochore oscillations? In principle, all proteins that can affect the dynamics of kinetochore microtubule plus-ends can fulfill this role: (1) microtubule depolymerases such as MCAK and Kif18A [101, 103, 135], (2) plus-end binding proteins, such EB1, CLASP, and Clip-170, which can favor microtubule growth and could thus regulate the speed of the poleward-moving sister kinetochore [136], and (3) microtubule-motor proteins, such as CENP-E or dynein, which could mechanically accelerate or slow down microtubule depolymerization. The best candidates at this stage are the kinetochore-bound microtubule depolymerases. The kinesin-13 MCAK has been implicated in microtubule turnover at the plus-end and the directional coordination between sister kinetochores [105]. Even more promising, depletion of the kinesin Kif18A was shown to lead to an increase in sister kinetochore oscillations due to increased oscillation speed and longer oscillation period, suggesting that the particular rate of microtubule dynamics at each sister kinetochore determines the oscillatory behavior [113]. It is important to note that Kif18A is a motile kinesin, and thus it is unclear whether it acts purely as a microtubule depolymerase or whether its ability to walk along microtubules also plays a role in chromosome alignment [135]. Interestingly, Kif18A is distributed asymmetrically on both sister kinetochores and the functional ortholog of Kif18A in S. cerevisiae is known to accumulate on microtubules in a length-dependent manner [113, 137]. This suggests a potential oscillation model in which the progressive lengthening of the $\mathrm{K}$-fiber at the anti-poleward-moving kinetochore accumulates more and more Kif18A to a certain threshold level at which it switches direction, thus releasing again the accumulated Kif18A [138]. However, at this stage, this remains a speculative model and certainly more molecular players that regulate chromosome oscillations remain to be identified, in particular the proteins that might regulate microtubule dynamics at the poleward-moving sister kinetochore. 


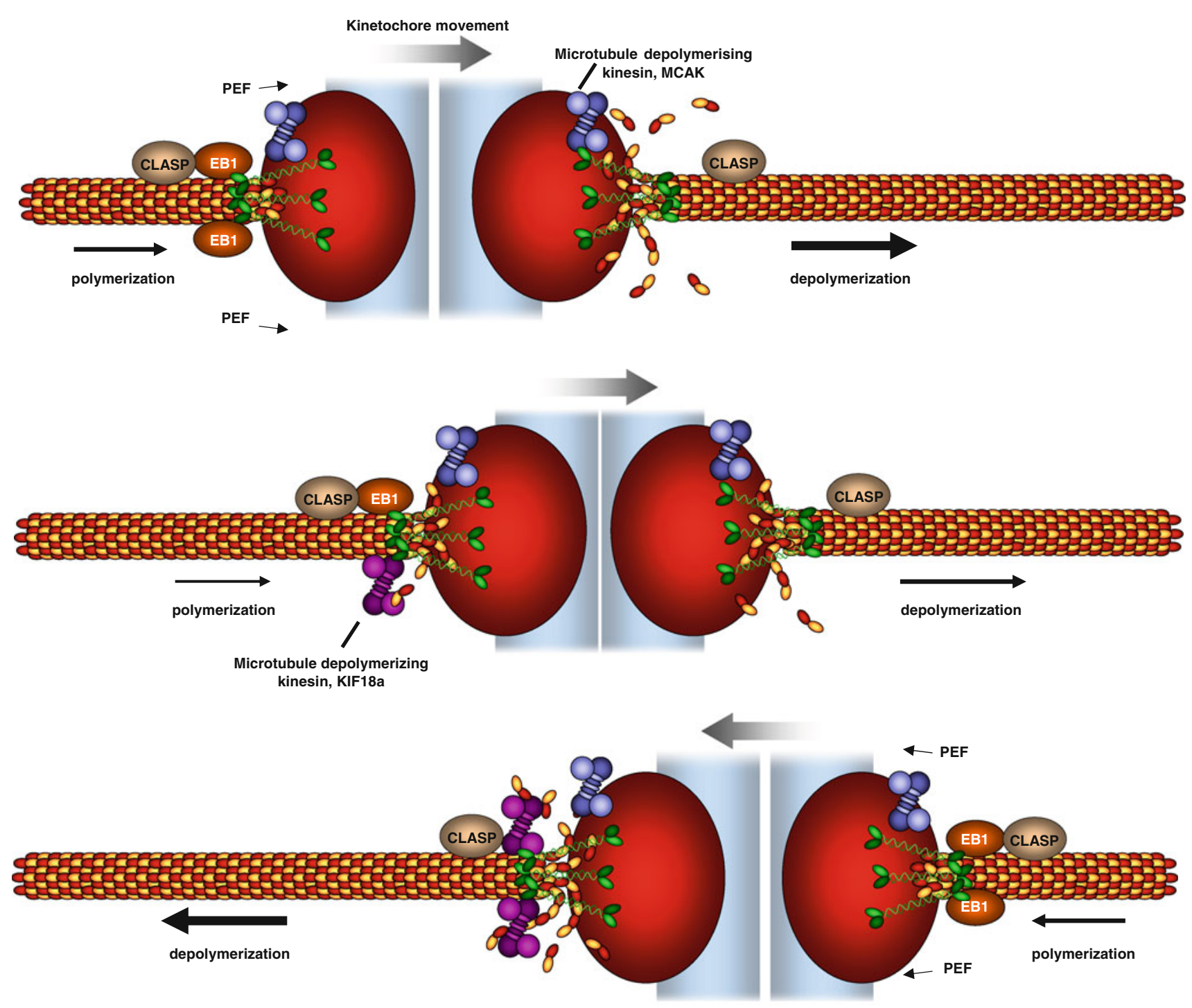

Fig. 4 Controlling chromosome movement on the metaphase plate. Bioriented sister kinetochores undergo regular oscillations on the metaphase plate. The direction of chromosome movement is primarily dictated by the pulling forces exerted by plus-end microtubule depolymerization. One proposed regulator of microtubule depolymerization is the microtubule depolymerase MCAK, a kinesin-13. Kinetochore movement is also assisted by microtubule polymerization at the lagging sister kinetochore, which could be promoted by EB1 and requires CLASP. One proposed model for the control of the chromosome oscillations is that the microtubule depolymerase Kif18a accumulates in a length-dependent manner on microtubules, leading to a gradual increase of Kif18a on the lagging kinetochores. As a

\section{Outstanding issues for future research}

The rapid development of novel tools to study chromosome congression, in particular those based on fast livecell imaging assays, imaging-based activity reporter assays, high-resolution measurement of microtubule dynamics, and high-throughput RNAi screening threshold of Kif18a is achieved, microtubule depolymerization is initiated at the lagging kinetochore, leading to a switch in direction. Note that this schematic is simplified for the purpose of clarity. It depicts one microtubule interacting with the kinetochore, even though in metazoans K-fibers are assembled from up to 25-30 bundled microtubules, raising the question as to how these multiple microtubules are coordinated with each other. Moreover, CLASP and MCAK are known to have more than one attachment site (Clip-170 on microtubule plus-ends and CENP-E on kinetochores for CLASP; inner centromere and inner kinetochore for MCAK [99, 175, 176]) implying a further level of regulation

technologies promises exciting times ahead for the detailed understanding of the molecular mechanisms that control chromosome congression. Here we present a number of open questions, which we think will be crucial to answer in future research directions. This list is by no means exhaustive but rather represents a subjective selection: 
Which congression processes are regulated by protein phosphorylation?

Since the chromosome-congression processes described above are highly dynamic and need to be tightly coordinated in space and time, it is not surprising that numerous kinases have been implicated in the regulation of congression. These include Mps1, BubR1, Bub1, Plk1, Aurora A, Aurora B, and Cdk1 [86, 96, 139-146]. Given that some kinases have been reported to be part of the same signaling pathways (e.g., Mps1-Aurora B, Cdk1Plk1-Aurora A, or Plk1-BubR1 [145, 147-151]), it is unlikely that each contributes a unique function to congression. Nevertheless, each pathway may control multiple events at multiple levels. For example, as alluded to earlier, Aurora B may have multiple substrates that promote error-correction (e.g., Ndc80 and MCAK) and some of these and others, like the kinesin-13 proteins MCAK, Kif2A, and Kif2B, may in addition contribute to chromosome alignment and oscillations. To get meaningful insight into the relevant modifications that regulate chromosome congression, it will be important to map the signaling networks that are active in prometaphase and to identify the substrates and phosphorylation sites that are controlled by these kinases. Such knowledge can be then used in RNAi complementation assays to reconstruct the function of a single phosphorylation site. A second important tool will be the development of live-cell probes which allow the measurement of the temporal and spatial pattern of kinase activity during cell division, as has been shown for Aurora B or Plk1 [150, 152]. However, one has to keep in mind that such probes might not always be specific and can reflect the activity of several kinases [150]. A third crucial set of tools will be the identification or design of small-molecule inhibitors to these kinases $[96,97,140,153,154]$ or the use of chemical genetics to label relevant substrates [155], as they offer a high temporal resolution for perturbation experiments. Finally, it will be important to assess whether kinetochore biology is entirely dominated by the varying activity of protein kinases, with protein phosphatases only providing a constitutive counteracting background, or if protein phosphatases play an active role at precise stages of chromosome segregation as has been recently reported for PP1 and the spindle checkpoint in budding and fission yeast $[156,157]$.

Why do sister kinetochores oscillate along the spindle axis?

Sister-kinetochore oscillations are observed in the vast majority of metazoan cells with the exception of insect cells such as those of D. melanogaster. However, to date, the function of these oscillations is not defined. Are they necessary for chromosome alignment as part of an evolutionary conserved mechanism as has been proposed [158], or do they just represent a downstream non-functional consequence of the dynamic instability of K-fibers themselves? Experiments in human cells indicate that Kif18A RNAi leads to an increase in the oscillation speed and modification of the chromosome oscillation period that correlates with a deregulation of metaphase plate organization [113]. This implies that kinetochore oscillations are important for metaphase plate alignment, but does not necessarily demonstrate why cells use this particular type of chromosome movement to find the middle of the spindle, as opposed to more direct chromosome movement. Moreover, if sister-kinetochore oscillations are important for chromosome alignment, why are they not present in D. melanogaster cells, and what alternative mechanism do these cells use to align their chromosomes on a metaphase plate? We believe that the answer to these questions will reside in the ability to modulate sister-kinetochore oscillations specifically, and test the extent to which this perturbs metaphase plate morphology. A second important aspect will be to compare these data with existing models of kinetochore oscillations to ultimately understand why this type of movement has been so well conserved in the course of evolution [158].

What is the importance of activity gradients for chromosome congression?

Research activities in the last 10 years have revealed the existence of several chromosome-associated activity-gradients that control multiple aspects of chromosome segregation. The most prominent example is the Ran-GTP gradient, which controls the activation of several spindleassociated factors in the vicinity of chromosomes, as RanGTP releases multiple proteins from an inhibitory binding by importin- $\alpha$ or importin- $\beta[56,159,160]$. Most of these proteins have been implicated in microtubule nucleation and bipolar spindle formation. While the Ran-GTP-gradient is essential for bipolar spindle assembly in embryonic systems, in somatic cells it appears that kinetochores in conjunction with centrosomes are the determining factors that control bipolar spindle assembly [56, 161]. Interestingly, several regulators and binding partners of Ran-GTP, such as the Ran-GAP, Ran-BP2, and Crm1 accumulate at kinetochores during mitosis and have been proposed to contribute to chromosome alignment through Ran-GTP [162-164]. However, to date, it is unclear whether these factors have a kinetochore-specific role during mitosis that is independent of the Ran-GTP gradient, or whether, in contrast to the kinetochores, they use the positional cue of the Ran-GTP gradient to fine-tune metaphase plate 
alignment during prometaphase. The second known activity gradient is based on phosphorylation of Aurora B substrates [152]. The Aurora B gradient is, as the Ran-GTP gradient, centered around chromosomes during prometaphase and metaphase. In contrast to Ran-GTP, however, Aurora B does not appear to leave the chromosomes with high dynamics in the prometaphase [165], and it is thus likely that the gradient is set by the phosphatases that dephosphorylate Aurora B substrates. Although hypothetical at this stage, it is possible that the degree to which a particular Aurora B substrate is phosphorylated might provide a spatial cue for chromosome congression. However, since both Aurora B and Ran-GTP are involved in many biological processes and since their complete inhibition or abrogation leads to pleiotropic phenotypes, it is difficult to estimate to what extent such gradients participate in chromosome alignment. Perhaps modifying the steepness of the gradients by impairing or displacing the natural counteractors of Ran-GTP or Aurora B (Ran-GAP or a yet unidentified protein phosphatase, respectively) might answer this question.

How many chromosome congression mechanisms co-exist?

As alluded to earlier, nearly all depletions of involved kinetochore- or spindle-associated proteins lead only to a partial disruption of chromosome alignment. Indeed, with the exception of the depletion of the Ndc80 complex, a metaphase plate is often visible despite major chromosome congression defects. This either indicates that depletions are always inefficient or that chromosome congression relies on several partially parallel mechanisms that provide efficiency and robustness to this process. For example, the CENP-E kinesin is only essential for monooriented sister kinetochores that establish an initial attachment in very close proximity to the spindle poles, even though it might participate in the congression of many more chromosomes [91]. Such partial redundancy has therefore important implications for the phenotypic interpretation of a particular RNAi depletion or gene mutation: even though a given protein might be implicated in chromosome congression, its role might be hidden and would only become visible in a sensitized background. Therefore, a first critical task will be to generate a map of the different paths chromosomes can use to achieve chromosome alignment. One key approach would be to use "genetic epistasis" to identify additive or non-additive phenotypes and thus to differentiate and separate the existing chromosome-congression pathways [166]. A second interesting question will be to understand whether all these pathways act independently of each other or whether the cell uses a compensatory mechanism to correct for the absence of a particular pathway. This will have very important implications for the understanding of how the mitotic spindle as a whole achieves chromosome alignment.

How can kinetochores generate order from $\sim 25$ non-synchronous stochastic microtubules within a K-fiber to generate directional movement?

The relationship between the overall dynamics of the K-fibers versus the non-synchronous behavior of the individual microtubules within the K-fiber remains a mystery. We do not know how kinetochores coordinate the behavior of single microtubules to obtain directional movements. The main limitation is that the only technique that can resolve single microtubules within a K-fiber-electronmicroscopy-only allows a single snapshot, without any temporal resolution [120]. Given that we know that direction changes of sister-kinetochores pairs occur in the range of seconds [127], we will need techniques that allow quantification of both individual microtubule growth and shrinkage at such high temporal resolution. One very promising potential technical solution for this challenging question might come from new super-resolution lightmicroscopy techniques, which will allow monitoring of the behavior of individual microtubules in real-time settings [167-171].

What is the relationship between prometaphase/ metaphase chromosome movement and anaphase movement?

Kinetochores are not only essential for chromosome movements during chromosome congression but also play an essential role during anaphase chromosome segregation. There is substantial evidence that chromosome movements in anaphase are regulated in a manner that is different from prometaphase/metaphase. For example, while poleward microtubule flux appears to have no effect on chromosome alignment, it can play a major role in anaphase, both at the chromosome speed level and for the synchronization of movements of the individual chromosomes [126, 172174]. Moreover, the microtubule dynamics of the K-fiber appear to be very different between the different mitotic stages [121]. However, for many proteins that are involved in chromosome movement during prometaphase, it is unclear whether they also regulate anaphase movements. This is due to the fact that depletion or inactivation of these components leads to such drastic phenotypes prior to anaphase that effects on anaphase are hard to interpret. As an extreme example, we do not know whether kinetochores require the $\mathrm{Ndc} 80$ complex during anaphase, as one would presume, or whether its role is restricted to chromosome attachment during prometaphase and metaphase. The 
development or rediscovery of technical strategies that allow the inactivation of a particular protein or the disruption of a critical interaction with high temporal resolution will aid in solving these issues. For instance, the identification of small molecules that disrupt protein-protein interactions or enzymatic activities, or returning to the use of micro-injection of metaphase/anaphase cells might offer crucial insights into the function of kinetochore proteins in anaphase (see e.g., [61]).

\section{Concluding remarks}

From the moment the spindle microtubules start reaching out for the chromosomes, many highly dynamic processes are initiated and coordinated to ensure that each chromosome ends up at the metaphase plate prior to chromosome segregation. We have attempted to outline the most important of these processes and highlight some of the lacunas in our understanding of them. The rapid evolution and implementation of novel imaging techniques and the ability to perturb the processes and visualize them in many model organisms will certainly spur research efforts in the coming years. Although it may take quite some time, we're closing in on finding out how cells manage to congress and segregate all chromosomes without errors, over and over again.

Acknowledgments We thank all the members of the Kops and Meraldi groups for helpful discussion on this review. Work in the lab of G.K. is supported by the Cancer Genomics Center and grants from the Dutch Cancer Society, the Netherlands Organisation for Scientific Research (NWO) and the ERC. P.M. is supported by a EURYI award, a Swiss National Science Foundation-Förderungs professorship, the Swiss Cancer League, and the ETH Zurich.

Open Access This article is distributed under the terms of the Creative Commons Attribution Noncommercial License which permits any noncommercial use, distribution, and reproduction in any medium, provided the original author(s) and source are credited.

\section{References}

1. Waldeyer HWG (1888) Über Karyokinese und ihre Beziehungen zu den Befruchtungsvorgängen. Archiv für mikroskopische Anatomie und Entwicklungsmechanik 32:1-122

2. Flemming W (1879) Beitrage zur kenntnis der zelle und ihrer lebenserscheinungen. Arch Mikrosk Anat 18:302-436

3. Flemming W (1882) Zellsubstanz, Kern und Zelltheilung. F.C.W. Vogel. Leipzig

4. Boveri T (1902) Über mehrpolige Mitosen als Mittel zur Analyse des Zellkerns. Verh. d. phys.-med. Ges. 35:67-90

5. Sutton WS (1903) The chromosomes in heredity. Biol Bull 4:231-251

6. Morgan TH (1910) Sex-limited inheritance in Drosophila. Science 32:120-122
7. Boveri T (1914) Zur Frage der Entstehung maligner Tumoren. Gustav Fischer Verlag, Jena

8. Holland AJ, Cleveland DW (2009) Boveri revisited: chromosomal instability, aneuploidy and tumorigenesis. Nat Rev Mol Cell Biol 10:478-487

9. Storchova Z, Pellman D (2004) From polyploidy to aneuploidy, genome instability and cancer. Nat Rev Mol Cell Biol 5:45-54

10. Darlington CD (1937) Recent advances in cytology. P. Blakiston's Son \& Co, London

11. Nicklas RB, Arana P (1992) Evolution and the meaning of metaphase. J Cell Sci 102(Pt 4):681-690

12. Yu HS, Russell SD (1993) Three-dimensional ultrastructure of generative cell mitosis in the pollen tube of Nicotiana tabacum. Eur J Cell Biol 61:338-348

13. Liu B, Palevitz BA (1991) Kinetochore fiber formation in dividing generative cells of Tradescantia. Kinetochore reorientation associated with the transition between lateral microtubule interactions and end-on kinetochore fibers. J Cell Sci 98:475482

14. Palevitz BA (1990) Kinetochore behavior during generative cell division in Tradescantia virginiana. Protoplasma 157

15. Kubai DF (1978) Mitosis and fungal phylogeny. In: Heath IB (ed) Nuclear division in the fungi. Academic Press, New York, pp 177-229

16. Straight AF, Marshall WF, Sedat JW, Murray AW (1997) Mitosis in living budding yeast: anaphase A but no metaphase plate. Science 277:574-578

17. Paweletz N (2001) Walther Flemming: pioneer of mitosis research. Nat Rev Mol Cell Biol 2:72-75

18. Schrader F (1939) Kinetic regions in chromosomes. Nature 143:122

19. Schrader F (1944) Mitosis: the movement of chromosomes in cell division. Columbia University Press, New York

20. Sharp LW (1934) Introduction to cytology. McGraw-Hill, New York

21. Khodjakov A, Cole RW, McEwen BF, Buttle KF, Rieder CL (1997) Chromosome fragments possessing only one kinetochore can congress to the spindle equator. J Cell Biol 136:229-240

22. Brinkley BR, Zinkowski RP, Mollon WL, Davis FM, Pisegna MA, Pershouse M, Rao PN (1988) Movement and segregation of kinetochores experimentally detached from mammalian chromosomes. Nature 336:251-254

23. O'Connell CB, Loncarek J, Hergert P, Kourtidis A, Conklin DS, Khodjakov A (2008) The spindle assembly checkpoint is satisfied in the absence of interkinetochore tension during mitosis with unreplicated genomes. J Cell Biol 183:29-36

24. Rieder CL, Davison EA, Jensen LC, Cassimeris L, Salmon ED (1986) Oscillatory movements of monooriented chromosomes and their position relative to the spindle pole result from the ejection properties of the aster and half-spindle. J Cell Biol 103:581-591

25. Brouhard GJ, Hunt AJ (2005) Microtubule movements on the arms of mitotic chromosomes: polar ejection forces quantified in vitro. Proc Natl Acad Sci USA 102:13903-13908

26. Antonio C, Ferby I, Wilhelm H, Jones M, Karsenti E, Nebreda AR, Vernos I (2000) Xkid, a chromokinesin required for chromosome alignment on the metaphase plate. Cell 102:425-435

27. Funabiki H, Murray AW (2000) The Xenopus chromokinesin Xkid is essential for metaphase chromosome alignment and must be degraded to allow anaphase chromosome movement. Cell 102:411-424

28. Ganem NJ, Compton DA (2006) Functional roles of poleward microtubule flux during mitosis. Cell Cycle 5:481-485

29. Levesque AA, Compton DA (2001) The chromokinesin Kid is necessary for chromosome arm orientation and oscillation, but not congression, on mitotic spindles. J Cell Biol 154:1135-1146 
30. Santamaria A, Nagel S, Sillje HH, Nigg EA (2008) The spindle protein CHICA mediates localization of the chromokinesin Kid to the mitotic spindle. Curr Biol 18:723-729

31. DeLuca JG, Dong Y, Hergert P, Strauss J, Hickey JM, Salmon ED, McEwen BF (2005) Hec1 and nuf2 are core components of the kinetochore outer plate essential for organizing microtubule attachment sites. Mol Biol Cell 16:519-531

32. DeLuca JG, Gall WE, Ciferri C, Cimini D, Musacchio A, Salmon ED (2006) Kinetochore microtubule dynamics and attachment stability are regulated by Hec1. Cell 127:969-982

33. Martin-Lluesma S, Stucke VM, Nigg EA (2002) Role of Hec1 in spindle checkpoint signaling and kinetochore recruitment of Mad1/Mad2. Science 297:2267-2270

34. McCleland ML, Gardner RD, Kallio MJ, Daum JR, Gorbsky GJ, Burke DJ, Stukenberg PT (2003) The highly conserved Ndc80 complex is required for kinetochore assembly, chromosome congression, and spindle checkpoint activity. Genes Dev 17:101-114

35. Dujardin D, Wacker UI, Moreau A, Schroer TA, Rickard JE, De Mey JR (1998) Evidence for a role of CLIP-170 in the establishment of metaphase chromosome alignment. J Cell Biol 141:849-862

36. Emanuele MJ, Stukenberg PT (2007) Xenopus Cep57 is a novel kinetochore component involved in microtubule attachment. Cell 130:893-905

37. Gaitanos TN, Santamaria A, Jeyaprakash AA, Wang B, Conti E, Nigg EA (2009) Stable kinetochore-microtubule interactions depend on the Ska complex and its new component Ska3/ C13Orf3. EMBO J 28:1442-1452

38. Hanisch A, Sillje HH, Nigg EA (2006) Timely anaphase onset requires a novel spindle and kinetochore complex comprising Ska1 and Ska2. EMBO J 25:5504-5515

39. Mao Y, Desai A, Cleveland DW (2005) Microtubule capture by CENP-E silences BubR1-dependent mitotic checkpoint signaling. J Cell Biol 170:873-880

40. McEwen BF, Chan GK, Zubrowski B, Savoian MS, Sauer MT, Yen TJ (2001) CENP-E is essential for reliable bioriented spindle attachment, but chromosome alignment can be achieved via redundant mechanisms in mammalian cells. Mol Biol Cell 12:2776-2789

41. Momotani K, Khromov AS, Miyake T, Stukenberg PT, Somlyo AV (2008) Cep57, a multidomain protein with unique microtubule and centrosomal localization domains. Biochem $\mathrm{J}$ 412:265-273

42. Pierre P, Scheel J, Rickard JE, Kreis TE (1992) CLIP-170 links endocytic vesicles to microtubules. Cell 70:887-900

43. Putkey FR, Cramer T, Morphew MK, Silk AD, Johnson RS, McIntosh JR, Cleveland DW (2002) Unstable kinetochoremicrotubule capture and chromosomal instability following deletion of CENP-E. Dev Cell 3:351-365

44. Raaijmakers JA, Tanenbaum ME, Maia AF, Medema RH (2009) RAMA1 is a novel kinetochore protein involved in kinetochoremicrotubule attachment. J Cell Sci 122:2436-2445

45. Tanenbaum ME, Galjart N, van Vugt MA, Medema RH (2006) CLIP-170 facilitates the formation of kinetochore-microtubule attachments. EMBO J 25:45-57

46. Theis M, Slabicki M, Junqueira M, Paszkowski-Rogacz M, Sontheimer J, Kittler R, Heninger AK, Glatter T, Kruusmaa K, Poser I, Hyman AA, Pisabarro MT, Gstaiger M, Aebersold R, Shevchenko A, Buchholz F (2009) Comparative profiling identifies C13orf3 as a component of the Ska complex required for mammalian cell division. EMBO J 28:1453-1465

47. Welburn JP, Grishchuk EL, Backer CB, Wilson-Kubalek EM, Yates JR 3rd, Cheeseman IM (2009) The human kinetochore Ska1 complex facilitates microtubule depolymerization-coupled motility. Dev Cell 16:374-385
48. Cai S, O’Connell CB, Khodjakov A, Walczak CE (2009) Chromosome congression in the absence of kinetochore fibres. Nat Cell Biol 11:832-838

49. Heald R, Tournebize R, Blank T, Sandaltzopoulos R, Becker P, Hyman A, Karsenti E (1996) Self-organization of microtubules into bipolar spindles around artificial chromosomes in Xenopus egg extracts. Nature 382:420-425

50. Gaetz J, Gueroui Z, Libchaber A, Kapoor TM (2006) Examining how the spatial organization of chromatin signals influences metaphase spindle assembly. Nat Cell Biol 8:924-932

51. Wood KW, Sakowicz R, Goldstein LS, Cleveland DW (1997) CENP-E is a plus end-directed kinetochore motor required for metaphase chromosome alignment. Cell 91:357-366

52. O'Connell CB, Khodjakov AL (2007) Cooperative mechanisms of mitotic spindle formation. J Cell Sci 120:1717-1722

53. Walczak CE, Heald R (2008) Mechanisms of mitotic spindle assembly and function. Int Rev Cytol 265:111-158

54. Hayden JH, Bowser SS, Rieder CL (1990) Kinetochores capture astral microtubules during chromosome attachment to the mitotic spindle: direct visualization in live newt lung cells. J Cell Biol 111:1039-1045

55. Rieder CL, Alexander SP (1990) Kinetochores are transported poleward along a single astral microtubule during chromosome attachment to the spindle in newt lung cells. J Cell Biol 110:8195

56. Clarke PR, Zhang C (2008) Spatial and temporal coordination of mitosis by Ran GTPase. Nat Rev Mol Cell Biol 9:464-477

57. Maiato H, Rieder CL, Khodjakov A (2004) Kinetochore-driven formation of kinetochore fibers contributes to spindle assembly during animal mitosis. J Cell Biol 167:831-840

58. Paschal BM, Vallee RB (1987) Retrograde transport by the microtubule-associated protein MAP 1C. Nature 330:181-183

59. Li Y, Yu W, Liang Y, Zhu X (2007) Kinetochore dynein generates a poleward pulling force to facilitate congression and full chromosome alignment. Cell Res 17:701-712

60. Yang Z, Tulu US, Wadsworth P, Rieder CL (2007) Kinetochore dynein is required for chromosome motion and congression independent of the spindle checkpoint. Curr Biol 17:973-980

61. Vorozhko VV, Emanuele MJ, Kallio MJ, Stukenberg PT, Gorbsky GJ (2008) Multiple mechanisms of chromosome movement in vertebrate cells mediated through the $\mathrm{Ndc} 80$ complex and dynein/dynactin. Chromosoma 117:169-179

62. Howell BJ, McEwen BF, Canman JC, Hoffman DB, Farrar EM, Rieder CL, Salmon ED (2001) Cytoplasmic dynein/dynactin drives kinetochore protein transport to the spindle poles and has a role in mitotic spindle checkpoint inactivation. J Cell Biol 155:1159-1172

63. Echeverri CJ, Paschal BM, Vaughan KT, Vallee RB (1996) Molecular characterization of the $50-\mathrm{kD}$ subunit of dynactin reveals function for the complex in chromosome alignment and spindle organization during mitosis. J Cell Biol 132:617-633

64. Savoian MS, Goldberg ML, Rieder CL (2000) The rate of poleward chromosome motion is attenuated in Drosophila zw10 and rod mutants. Nat Cell Biol 2:948-952

65. Starr DA, Williams BC, Hays TS, Goldberg ML (1998) ZW10 helps recruit dynactin and dynein to the kinetochore. J Cell Biol 142:763-774

66. Bomont P, Maddox P, Shah JV, Desai AB, Cleveland DW (2005) Unstable microtubule capture at kinetochores depleted of the centromere-associated protein CENP-F. EMBO J 24:39273939

67. Chan YW, Fava LL, Uldschmid A, Schmitz MH, Gerlich DW, Nigg EA, Santamaria A (2009) Mitotic control of kinetochoreassociated dynein and spindle orientation by human Spindly. J Cell Biol 185:859-874 
68. Vergnolle MA, Taylor SS (2007) CENP-F links kinetochores to Ndel1/Nde1/Lis1/dynein microtubule motor complexes. Curr Biol 17:1173-1179

69. Stehman SA, Chen Y, McKenney RJ, Vallee RB (2007) NudE and NudEL are required for mitotic progression and are involved in dynein recruitment to kinetochores. J Cell Biol 178:583-594

70. Griffis ER, Stuurman N, Vale RD (2007) Spindly, a novel protein essential for silencing the spindle assembly checkpoint, recruits dynein to the kinetochore. J Cell Biol 177:1005-1015

71. Varma D, Monzo P, Stehman SA, Vallee RB (2008) Direct role of dynein motor in stable kinetochore-microtubule attachment, orientation, and alignment. J Cell Biol 182:1045-1054

72. Tanaka TU, Desai A (2008) Kinetochore-microtubule interactions: the means to the end. Curr Opin Cell Biol 20:53-63

73. Miranda JJ, De Wulf P, Sorger PK, Harrison SC (2005) The yeast DASH complex forms closed rings on microtubules. Nat Struct Mol Biol 12:138-143

74. Westermann S, Avila-Sakar A, Wang HW, Niederstrasser H, Wong J, Drubin DG, Nogales E, Barnes G (2005) Formation of a dynamic kinetochore-microtubule interface through assembly of the Dam1 ring complex. Mol Cell 17:277-290

75. Gestaut DR, Graczyk B, Cooper J, Widlund PO, Zelter A, Wordeman L, Asbury CL, Davis TN (2008) Phosphoregulation and depolymerization-driven movement of the Dam1 complex do not require ring formation. Nat Cell Biol 10:407-414

76. Tanaka K, Kitamura E, Kitamura Y, Tanaka TU (2007) Molecular mechanisms of microtubule-dependent kinetochore transport toward spindle poles. J Cell Biol 178:269-281

77. Meraldi P, McAinsh AD, Rheinbay E, Sorger PK (2006) Phylogenetic and structural analysis of centromeric DNA and kinetochore proteins. Genome Biol 7:R23

78. Powers AF, Franck AD, Gestaut DR, Cooper J, Gracyzk B, Wei RR, Wordeman L, Davis TN, Asbury CL (2009) The Ndc80 kinetochore complex forms load-bearing attachments to dynamic microtubule tips via biased diffusion. Cell 136:865-875

79. Grishchuk EL, Efremov AK, Volkov VA, Spiridonov IS, Gudimchuk N, Westermann S, Drubin D, Barnes G, McIntosh JR, Ataullakhanov FI (2008) The Dam1 ring binds microtubules strongly enough to be a processive as well as energy-efficient coupler for chromosome motion. Proc Natl Acad Sci USA 105:15423-15428

80. Westermann S, Wang HW, Avila-Sakar A, Drubin DG, Nogales E, Barnes G (2006) The Dam1 kinetochore ring complex moves processively on depolymerizing microtubule ends. Nature 440:565-569

81. Gassmann R, Essex A, Hu JS, Maddox PS, Motegi F, Sugimoto A, O'Rourke SM, Bowerman B, McLeod I, Yates JR 3rd, Oegema K, Cheeseman IM, Desai A (2008) A new mechanism controlling kinetochore-microtubule interactions revealed by comparison of two dynein-targeting components: SPDL-1 and the Rod/Zwilch/Zw10 complex. Genes Dev 22:2385-2399

82. Cheeseman IM, Chappie JS, Wilson-Kubalek EM, Desai A (2006) The conserved KMN network constitutes the core microtubule-binding site of the kinetochore. Cell 127:983-997

83. Ciferri C, Pasqualato S, Screpanti E, Varetti G, Santaguida S, Dos Reis G, Maiolica A, Polka J, De Luca JG, De Wulf P, Salek M, Rappsilber J, Moores CA, Salmon ED, Musacchio A (2008) Implications for kinetochore-microtubule attachment from the structure of an engineered Ndc80 complex. Cell 133:427-439

84. Lampson MA, Renduchitala K, Khodjakov A, Kapoor TM (2004) Correcting improper chromosome-spindle attachments during cell division. Nat Cell Biol 6:232-237

85. Maddox PS, Oegema K, Desai A, Cheeseman IM (2004) "Holo"er than thou: chromosome segregation and kinetochore function in C. elegans. Chromosome Res 12:641-653
86. Meraldi P, Sorger PK (2005) A dual role for Bub1 in the spindle checkpoint and chromosome congression. EMBO J 24:16211633

87. Gillett ES, Espelin CW, Sorger PK (2004) Spindle checkpoint proteins and chromosome-microtubule attachment in budding yeast. J Cell Biol 164:535-546

88. Klebig C, Korinth D, Meraldi P (2009) Bub1 regulates chromosome segregation in a kinetochore-independent manner. J Cell Biol 185:841-858

89. Warren CD, Brady DM, Johnston RC, Hanna JS, Hardwick KG, Spencer FA (2002) Distinct chromosome segregation roles for spindle checkpoint proteins. Mol Biol Cell 13:3029-3041

90. Rieder CL (2005) Kinetochore fiber formation in animal somatic cells: dueling mechanisms come to a draw. Chromosoma 114:310-318

91. Kapoor TM, Lampson MA, Hergert P, Cameron L, Cimini D, Salmon ED, McEwen BF, Khodjakov A (2006) Chromosomes can congress to the metaphase plate before biorientation. Science 311:388-391

92. Loncarek J, Kisurina-Evgenieva O, Vinogradova T, Hergert P, La Terra S, Kapoor TM, Khodjakov A (2007) The centromere geometry essential for keeping mitosis error free is controlled by spindle forces. Nature 450:745-749

93. Nicklas RB, Kubai DF (1985) Microtubules, chromosome movement, and reorientation after chromosomes are detached from the spindle by micromanipulation. Chromosoma 92:313-324

94. Cimini D, Fioravanti D, Salmon ED, Degrassi F (2002) Merotelic kinetochore orientation versus chromosome monoorientation in the origin of lagging chromosomes in human primary cells. J Cell Sci 115:507-515

95. Cimini D, Wan X, Hirel CB, Salmon ED (2006) Aurora kinase promotes turnover of kinetochore microtubules to reduce chromosome segregation errors. Curr Biol 16:1711-1718

96. Ditchfield C, Johnson VL, Tighe A, Ellston R, Haworth C, Johnson T, Mortlock A, Keen N, Taylor SS (2003) Aurora B couples chromosome alignment with anaphase by targeting BubR1, Mad2, and Cenp-E to kinetochores. J Cell Biol 161:267-280

97. Hauf S, Cole RW, LaTerra S, Zimmer C, Schnapp G, Walter R, Heckel A, van Meel J, Rieder CL, Peters JM (2003) The smallmolecule Hesperadin reveals a role for Aurora B in correcting kinetochore-microtubule attachment and in maintaining the spindle assembly checkpoint. J Cell Biol 161:281-294

98. Guimaraes GJ, Dong Y, McEwen BF, Deluca JG (2008) Kinetochore-microtubule attachment relies on the disordered N-terminal tail domain of Hec1. Curr Biol 18:1778-1784

99. Andrews PD, Ovechkina Y, Morrice N, Wagenbach M, Duncan K, Wordeman L, Swedlow JR (2004) Aurora B regulates MCAK at the mitotic centromere. Dev Cell 6:253-268

100. Desai A, Verma S, Mitchison TJ, Walczak CE (1999) Kin I kinesins are microtubule-destabilizing enzymes. Cell 96:69-78

101. Hunter AW, Caplow M, Coy DL, Hancock WO, Diez S, Wordeman L, Howard J (2003) The kinesin-related protein MCAK is a microtubule depolymerase that forms an ATPhydrolyzing complex at microtubule ends. Mol Cell 11:445-457

102. Barr FA, Sillje HH, Nigg EA (2004) Polo-like kinases and the orchestration of cell division. Nat Rev Mol Cell Biol 5:429-440

103. Wordeman L, Mitchison TJ (1995) Identification and partial characterization of mitotic centromere-associated kinesin, a kinesin-related protein that associates with centromeres during mitosis. J Cell Biol 128:95-104

104. Knowlton AL, Lan W, Stukenberg PT (2006) Aurora B is enriched at merotelic attachment sites, where it regulates MCAK. Curr Biol 16:1705-1710

105. Wordeman L, Wagenbach M, von Dassow G (2007) MCAK facilitates chromosome movement by promoting kinetochore microtubule turnover. J Cell Biol 179:869-879 
106. Gadea BB, Ruderman JV (2006) Aurora B is required for mitotic chromatin-induced phosphorylation of Op18/Stathmin. Proc Natl Acad Sci USA 103:4493-4498

107. Knowlton AL, Vorozhko VV, Lan W, Gorbsky GJ, Stukenberg PT (2009) ICIS and Aurora B coregulate the microtubule depolymerase Kif2a. Curr Biol 19:758-763

108. Bakhoum SF, Thompson SL, Manning AL, Compton DA (2009) Genome stability is ensured by temporal control of kinetochoremicrotubule dynamics. Nat Cell Biol 11:27-35

109. Tanaka TU, Rachidi N, Janke C, Pereira G, Galova M, Schiebel E, Stark MJ, Nasmyth K (2002) Evidence that the Ipl1-Sli15 (Aurora kinase-INCENP) complex promotes chromosome bi-orientation by altering kinetochore-spindle pole connections. Cell 108:317-329

110. Liu D, Vader G, Vromans MJ, Lampson MA, Lens SM (2009) Sensing chromosome bi-orientation by spatial separation of aurora B kinase from kinetochore substrates. Science 323:1350-1353

111. Oestergren G (1945) Equilibrium of trivalents and the mechanism of chromosome movement. Hereditas 31:498

112. Cai S, Weaver LN, Ems-McClung SC, Walczak CE (2009) Kinesin-14 family proteins HSET/XCTK2 control spindle length by cross-linking and sliding microtubules. Mol Biol Cell 20:1348-1359

113. Stumpff J, von Dassow G, Wagenbach M, Asbury C, Wordeman L (2008) The kinesin-8 motor Kif18A suppresses kinetochore movements to control mitotic chromosome alignment. Dev Cell $14: 252-262$

114. Peterson JB, Ris H (1976) Electron-microscopic study of the spindle and chromosome movement in the yeast Saccharomyces cerevisiae. J Cell Sci 22:219-242

115. Maiato H, Hergert PJ, Moutinho-Pereira S, Dong $Y$, Vandenbeldt KJ, Rieder CL, McEwen BF (2006) The ultrastructure of the kinetochore and kinetochore fiber in Drosophila somatic cells. Chromosoma 115:469-480

116. Lin HP, Ault JG, Church K (1981) Meiosis in Drosophila melanogaster. I. Chromosome identification and kinetochore microtubule numbers during the first and second meiotic divisions in males. Chromosoma 83:507-521

117. Rieder CL (1982) The formation, structure, and composition of the mammalian kinetochore and kinetochore fiber. Int Rev Cytol 79:1-58

118. Ding R, McDonald KL, McIntosh JR (1993) Three-dimensional reconstruction and analysis of mitotic spindles from the yeast, Schizosaccharomyces pombe. J Cell Biol 120:141-151

119. Tirnauer JS, Canman JC, Salmon ED, Mitchison TJ (2002) EB1 targets to kinetochores with attached, polymerizing microtubules. Mol Biol Cell 13:4308-4316

120. VandenBeldt KJ, Barnard RM, Hergert PJ, Meng X, Maiato H, McEwen BF (2006) Kinetochores use a novel mechanism for coordinating the dynamics of individual microtubules. Curr Biol 16:1217-1223

121. Zhai Y, Kronebusch PJ, Borisy GG (1995) Kinetochore microtubule dynamics and the metaphase-anaphase transition. J Cell Biol 131:721-734

122. Mitchison TJ (1989) Polewards microtubule flux in the mitotic spindle: evidence from photoactivation of fluorescence. J Cell Biol 109:637-652

123. Maiato H, Khodjakov A, Rieder CL (2005) Drosophila CLASP is required for the incorporation of microtubule subunits into fluxing kinetochore fibres. Nat Cell Biol 7:42-47

124. Waters JC, Mitchison TJ, Rieder CL, Salmon ED (1996) The kinetochore microtubule minus-end disassembly associated with poleward flux produces a force that can do work. Mol Biol Cell 7:1547-1558

125. Toso A, Winter JR, Garrod AJ, Amaro AC, Meraldi P, McAinsh AD (2009) Kinetochore-generated pushing forces separate centrosomes during bipolar spindle assembly. J Cell Biol 184:365-372

126. Ganem NJ, Upton K, Compton DA (2005) Efficient mitosis in human cells lacking poleward microtubule flux. Curr Biol 15:1827-1832

127. Skibbens RV, Skeen VP, Salmon ED (1993) Directional instability of kinetochore motility during chromosome congression and segregation in mitotic newt lung cells: a push-pull mechanism. J Cell Biol 122:859-875

128. Lewis WH (1939) Changes of viscosity and cell activity. Science 89:400

129. Hughes AF, Swann MM (1948) Anaphase movements in the living cell. J Exp Biol 25:45-70

130. Molé-Bajer J, Bajer A, Owczarzak A (1975) Chromosome movements in prometaphase and aster transport in the newt. Cytobios 13:45-65

131. Seto T, Kezer J, Pomerat CM (1969) A cinematographic study of meiosis in salamander spermatocytes in vitro. Z Zellforsch Mikrosk Anat 94:407-424

132. Khodjakov A, Rieder CL (1996) Kinetochores moving away from their associated pole do not exert a significant pushing force on the chromosome. J Cell Biol 135:315-327

133. Silk AD, Holland AJ, Cleveland DW (2009) Requirements for NuMA in maintenance and establishment of mammalian spindle poles. J Cell Biol 184:677-690

134. Ke K, Cheng J, Hunt AJ (2009) The distribution of polar ejection forces determines the amplitude of chromosome directional instability. Curr Biol 19:807-815

135. Mayr MI, Hummer S, Bormann J, Gruner T, Adio S, Woehlke G, Mayer TU (2007) The human kinesin Kif18A is a motile microtubule depolymerase essential for chromosome congression. Curr Biol 17:488-498

136. Akhmanova A, Steinmetz MO (2008) Tracking the ends: a dynamic protein network controls the fate of microtubule tips. Nat Rev Mol Cell Biol 9:309-322

137. Varga V, Helenius J, Tanaka K, Hyman AA, Tanaka TU, Howard J (2006) Yeast kinesin-8 depolymerizes microtubules in a length-dependent manner. Nat Cell Biol 8:957-962

138. Gardner MK, Odde DJ, Bloom K (2008) Kinesin-8 molecular motors: putting the brakes on chromosome oscillations. Trends Cell Biol 18:307-310

139. Espeut J, Gaussen A, Bieling P, Morin V, Prieto S, Fesquet D, Surrey T, Abrieu A (2008) Phosphorylation relieves autoinhibition of the kinetochore motor Cenp-E. Mol Cell 29:637-643

140. Lenart P, Petronczki M, Steegmaier M, Di Fiore B, Lipp JJ, Hoffmann M, Rettig WJ, Kraut N, Peters JM (2007) The smallmolecule inhibitor BI 2536 reveals novel insights into mitotic roles of polo-like kinase 1. Curr Biol 17:304-315

141. Jang CY, Coppinger JA, Seki A, Yates JR 3rd, Fang G (2009) Plk1 and Aurora A regulate the depolymerase activity and the cellular localization of Kif2a. J Cell Sci 122:1334-1341

142. Wong J, Lerrigo R, Jang CY, Fang G (2008) Aurora A regulates the activity of HURP by controlling the accessibility of its microtubule-binding domain. Mol Biol Cell 19:2083-2091

143. Johnson VL, Scott MI, Holt SV, Hussein D, Taylor SS (2004) Bub1 is required for kinetochore localization of BubR1, Cenp-E, Cenp-F and Mad2, and chromosome congression. J Cell Sci 117:1577-1589

144. Lampson MA, Kapoor TM (2005) The human mitotic checkpoint protein BubR1 regulates chromosome-spindle attachments. Nat Cell Biol 7:93-98

145. Jelluma N, Brenkman AB, van den Broek NJ, Cruijsen CW, van Osch MH, Lens SM, Medema RH, Kops GJ (2008) Mps1 phosphorylates Borealin to control Aurora B activity and chromosome alignment. Cell 132:233-246 
146. Maure JF, Kitamura E, Tanaka TU (2007) Mps1 kinase promotes sister-kinetochore bi-orientation by a tension-dependent mechanism. Curr Biol 17:2175-2182

147. Elowe S, Hummer S, Uldschmid A, Li X, Nigg EA (2007) Tension-sensitive Plk1 phosphorylation on BubR1 regulates the stability of kinetochore microtubule interactions. Genes Dev 21:2205-2219

148. Wong OK, Fang G (2007) Cdk1 phosphorylation of BubR1 controls spindle checkpoint arrest and Plk1-mediated formation of the 3F3/2 epitope. J Cell Biol 179:611-617

149. Seki A, Coppinger JA, Jang CY, Yates JR, Fang G (2008) Bora and the kinase Aurora a cooperatively activate the kinase Plk1 and control mitotic entry. Science 320:1655-1658

150. Macurek L, Lindqvist A, Lim D, Lampson MA, Klompmaker R, Freire R, Clouin C, Taylor SS, Yaffe MB, Medema RH (2008) Polo-like kinase-1 is activated by aurora A to promote checkpoint recovery. Nature 455:119-123

151. Matsumura S, Toyoshima F, Nishida E (2007) Polo-like kinase 1 facilitates chromosome alignment during prometaphase through BubR1. J Biol Chem 282:15217-15227

152. Fuller BG, Lampson MA, Foley EA, Rosasco-Nitcher S, Le KV, Tobelmann P, Brautigan DL, Stukenberg PT, Kapoor TM (2008) Midzone activation of aurora $\mathrm{B}$ in anaphase produces an intracellular phosphorylation gradient. Nature 453:1132-1136

153. Santamaria A, Neef R, Eberspacher U, Eis K, Husemann M, Mumberg D, Prechtl S, Schulze V, Siemeister G, Wortmann L, Barr FA, Nigg EA (2007) Use of the novel Plk1 inhibitor ZK-thiazolidinone to elucidate functions of Plk1 in early and late stages of mitosis. Mol Biol Cell 18:4024-4036

154. Hoar K, Chakravarty A, Rabino C, Wysong D, Bowman D, Roy N, Ecsedy JA (2007) MLN8054, a small-molecule inhibitor of Aurora A, causes spindle pole and chromosome congression defects leading to aneuploidy. Mol Cell Biol 27:4513-4525

155. Blethrow JD, Glavy JS, Morgan DO, Shokat KM (2008) Covalent capture of kinase-specific phosphopeptides reveals Cdk1-cyclin B substrates. Proc Natl Acad Sci USA 105:1442-1447

156. Vanoosthuyse V, Hardwick KG (2009) A novel protein phosphatase 1-dependent spindle checkpoint silencing mechanism. Curr Biol 19:1176-1181. doi:10.1016/j.cub.2009.05.060

157. Pinsky BA, Nelson CR, Biggins S (2009) Protein phosphatase 1 regulates exit from the spindle checkpoint in budding yeast. Curr Biol 19:1182-1187. doi:10.1016/j.cub.2009.06.043

158. Liu J, Desai A, Onuchic JN, Hwa T (2008) An integrated mechanobiochemical feedback mechanism describes chromosome motility from prometaphase to anaphase in mitosis. Proc Natl Acad Sci USA 105:13752-13757

159. Athale CA, Dinarina A, Mora-Coral M, Pugieux C, Nedelec F, Karsenti E (2008) Regulation of microtubule dynamics by reaction cascades around chromosomes. Science 322:1243-1247

160. Kalab P, Heald R (2008) The RanGTP gradient-a GPS for the mitotic spindle. J Cell Sci 121:1577-1586

161. O'Connell CB, Loncarek J, Kalab P, Khodjakov A (2009) Relative contributions of chromatin and kinetochores to mitotic spindle assembly. J Cell Biol 187:43-51

162. Arnaoutov A, Azuma Y, Ribbeck K, Joseph J, Boyarchuk Y, Karpova T, McNally J, Dasso M (2005) Crm1 is a mitotic effector of Ran-GTP in somatic cells. Nat Cell Biol 7:626-632
163. Joseph J, Liu ST, Jablonski SA, Yen TJ, Dasso M (2004) The RanGAP1-RanBP2 complex is essential for microtubule-kinetochore interactions in vivo. Curr Biol 14:611-617

164. Arnaoutov A, Dasso M (2003) The Ran GTPase regulates kinetochore function. Dev Cell 5:99-111

165. Delacour-Larose M, Hoang TM, Molla A (2008) Survivin, the starlet of the passenger-protein complex: check-up for its tenth anniversary. Med Sci (Paris) 24:828-832

166. McClelland SE, Borusu S, Amaro AC, Winter JR, Belwal M, McAinsh AD, Meraldi P (2007) The CENP-A NAC/CAD kinetochore complex controls chromosome congression and spindle bipolarity. EMBO J 26:5033-5047

167. Schermelleh L, Carlton PM, Haase S, Shao L, Winoto L, Kner P, Burke B, Cardoso MC, Agard DA, Gustafsson MG, Leonhardt H, Sedat JW (2008) Subdiffraction multicolor imaging of the nuclear periphery with $3 \mathrm{D}$ structured illumination microscopy. Science 320:1332-1336

168. Westphal V, Rizzoli SO, Lauterbach MA, Kamin D, Jahn R, Hell SW (2008) Video-rate far-field optical nanoscopy dissects synaptic vesicle movement. Science 320:246-249

169. Betzig E, Patterson GH, Sougrat R, Lindwasser OW, Olenych S, Bonifacino JS, Davidson MW, Lippincott-Schwartz J, Hess HF (2006) Imaging intracellular fluorescent proteins at nanometer resolution. Science 313:1642-1645

170. Shtengel G, Galbraith JA, Galbraith CG, Lippincott-Schwartz J, Gillette JM, Manley S, Sougrat R, Waterman CM, Kanchanawong P, Davidson MW, Fetter RD, Hess HF (2009) Interferometric fluorescent super-resolution microscopy resolves 3D cellular ultrastructure. Proc Natl Acad Sci USA 106:31253130

171. Willig KI, Rizzoli SO, Westphal V, Jahn R, Hell SW (2006) STED microscopy reveals that synaptotagmin remains clustered after synaptic vesicle exocytosis. Nature 440:935-939

172. Matos I, Pereira AJ, Lince-Faria M, Cameron LA, Salmon ED, Maiato H (2009) Synchronizing chromosome segregation by flux-dependent force equalization at kinetochores. J Cell Biol 186:11-26

173. Maddox P, Desai A, Oegema K, Mitchison TJ, Salmon ED (2002) Poleward microtubule flux is a major component of spindle dynamics and anaphase a in mitotic Drosophila embryos. Curr Biol 12:1670-1674

174. Desai A, Maddox PS, Mitchison TJ, Salmon ED (1998) Anaphase A chromosome movement and poleward spindle microtubule flux occur At similar rates in Xenopus extract spindles. J Cell Biol 141:703-713

175. Maffini S, Maia AR, Manning AL, Maliga Z, Pereira AL, Junqueira M, Shevchenko A, Hyman A, Yates JR 3rd, Galjart N, Compton DA, Maiato H (2009) Motor-independent targeting of CLASPs to kinetochores by CENP-E promotes microtubule turnover and poleward flux. Curr Biol 19:1566-1572

176. Akhmanova A, Hoogenraad CC, Drabek K, Stepanova T, Dortland B, Verkerk T, Vermeulen W, Burgering BM, De Zeeuw CI, Grosveld F, Galjart N (2001) Clasps are CLIP-115 and -170 associating proteins involved in the regional regulation of microtubule dynamics in motile fibroblasts. Cell 104:923-935 